\title{
EL SIGNIFICANTE DE LAS CATEGORÍAS MORFOLÓGICAS
}

\author{
Francisco J. Albertuz \\ (Universidad de Santiago de Compostela)
}

\begin{abstract}
RESUMEN
From a structuralistic point of view, a definition of the concept grammatical category necessarily requires a description of its semiotic status. In order to achieve this aim, several conceptions about minimum-sign expression are reviewed. After having analyzed phonic, syntagmatic (either in pure or mixed form) and other non-phonological (as Hockett's, 1961) theories, it is argued that minimumsign expression-form is not phonic but minimum-sign expression-substance is. This interpretation fits in with Hjelmslev's (1928) description of morphemes expression, and Hockett's (1958) and Lyons' (1968) accounts of the relations between morphemes and morphs. As conclusion, the entity minimum-sign (morpheme) is claimed to be the semiotic means by which grammatical categories perform their function in language.
\end{abstract}

\section{Introducción}

En una primera aproximación, tan inmediata como insuficiente, el concepto de categoría morfológica (o categoría gramatical') suele delimitarse mediante la enumeración del tipo de fenómenos más concretos que a él se asocian: género, número, caso, tiempo, modo, aspecto, etc. Las caracterizaciones extensivas poseen cierta utilidad desde el punto de vista práctico, como medio de ilustración rápida del sentido otorgado a una etiqueta terminológica, pero

1 Prefiero utilizar aquí el primero de los términos puesto que algunos autores (p.e. Bosque, 1989) emplean categoria gramatical para referirse a las clases de palabras (sustantivo, adjetivo, verbo...). 
carecen, evidentemente, de valor teórico. Al igual que en cualquier otro ámbito, un acercamiento riguroso a las categorías morfológicas exige la fundamentación precisa de esta noción, la especificación de sus rasgos definitorios. Un estudio exhaustivo de las categorías morfológicas debe incluir, en mi opinión, los siguientes aspectos:

1. Es imprescindible aclarar, en primer lugar, cuál es su estatus semiótico, especificando si se trata de signos (entidades biplanas, dotadas de significante y significado) o de figuras (unidades monoplanas, de la expresión o del contenido) y concretando, al tiempo, el tipo de fenómenos sustanciales a través de los que se manifiestan. Desde una perspectiva estructural como la que se asume en este trabajo, basada en la consideración de las lenguas como sistemas de comunicación integrados por diferentes tipos de unidades, esta delimitación resulta esencial y previa a cualquier otra consideración.

2. Es posible, sin embargo, que la descripción de su entidad semiótica no sea suficiente para individualizar a las categorías morfológicas frente a todos los restantes fenómenos linguísticos. En ese caso será necesario especificar qué otras propiedades las caracterizan de manera definitoria.

3. Un tercer objetivo, éste ya en otro nivel, viene dado por la comprobación de la existencia de correspondencia o no entre el inventario de categorías habitualmente reconocidas y el conjunto de fenómenos que reúnen las características especificadas anteriormente, lo que puede llevar a replantear o negar el valor categorial de algunas de ellas o, por el contrario, a reconocer la categorialidad de hechos no interpretados inicialmente como tales.

Los tres aspectos anteriores ${ }^{2}$ están encadenados, de tal modo que las conclusiones obtenidas en el primero condicionan el tratamiento del segundo (o, incluso, la necesidad misma de plantearlo), y ambos, a su vez, determinan las decisiones que se puedan adoptar en el tercero. Ciertamente, caben otras alternativas de análisis: por ejemplo, prescindir de $1 \mathrm{y}$, partiendo del inventario usual de categorías, reconocer en algún otro factor (de los que incluiríamos inicialmente en 2) la naturaleza definitoria de las mismas. Por diversas razones, teóricas y prácticas, creo que el orden sugerido es el más útil. Desatender el primero de los puntos es la forma más fácil de llegar a ignorar la heterogeneidad de los dominios categoriales generalmente aceptados. Ésta se revela en toda su magnitud cuando tratamos de situar una categoría (o hechos concretos reconocidos como pertenecientes a la misma) en el entramado de planos, estratos y componentes de las lenguas. Una vez advertida esa realidad, por otra parte, no

A los que hay que añadir, en el siguiente nivel de concreción, todo lo que tiene que ver con la estructuración interna de las categorías, tanto en el nivel de las lenguas particulares (descripción del sistema efectivo de valores) como en el nivel general (pautas de organización y márgenes de variación, expresables, por ejemplo, por medio de jerarquías tipológicas). 
existen dificultades para relegarla a un segundo plano si se estima que la posesión de una determinada configuración semiótica no es un requisito necesario para identificar una categoría morfológica y se juzga, en cambio, que es un rasgo de otro tipo - al que todas las categorías identificadas habitualmente como tales responden de manera homogénea- el que las define.

Las páginas siguientes estarán dedicadas en exclusiva a abordar esta primera cuestión: la naturaleza semiótica de las categorías morfológicas. A este respecto hay que señalar que las alternativas propuestas son, en sí mismas, limitadas: o se trata de signos mínimos ${ }^{3}$, o estamos, con un análisis necesariamente distinto, ante figuras del contenido (integrantes, a su vez, del significado de un signo mínimo). Dentro de la concepción sígnica, sin embargo, existe un notable grado de variación. Aun considerando las categorías como unidades biplanas, la interpretación concreta diverge - con las consiguientes repercusiones descriptivas- en función del tipo de fundamentación que se otorgue a cada uno de sus elementos constitutivos, especialmente al significante. Con carácter general, se puede decir que es precisamente la interpretación del significante y, ligado a ello, la de sus manifestaciones sustanciales, el factor de diferenciación de todas las propuestas sobre las categorías en el nivel de análisis que ahora nos ocupa. Por ello parece posible, y conveniente, delimitar de forma más precisa el objeto de estudio y estructurar así este trabajo como un recorrido por algunas de las principales concepciones del significante del signo mínimo ${ }^{4}$. El análisis y la evaluación de las mismas debe permitir ofrecer, finalmente, una alternativa teórica y descriptivamente adecuada.

\section{El significante del signo mínimo}

\subsection{El significante fónico}

La concepción claramente predominante del significante del signo mínimo es la que le atribuye carácter fónico. En esta visión, y sea cual sea, por lo demás, el modelo descriptivo concreto que se adopte ${ }^{5}$, el significante del signo se

3 O de los significados de éstos, lo que no entraña una interpretación diferente de los hechos.

4 Empleo la caracterización semiótica signo mínimo, sin adoptar por el momento ninguna denominación lingüística para éste, con el fin de evitar posibles confusiones terminológicas. En la exposición de las opiniones de cada autor combinaré los términos generales, inequívocos (signo mínimo, significante fónico, figura de contenido...), con las propias etiquetas que éste utilice, especialmente la de morfema. El término morfema, por tanto, habrá de ser interpretado en cada caso de acuerdo con el valor particular (explicitado a lo largo de la exposición) que ese autor le concede.

5 Sobre los modelos de descripción morfológica Item \& Arrangement, Item \& Process y Word \& Paradign, Cfr. Pena (1990). 
concibe como compuesto de fonemas. Las dificultades surgen cuando no es posible establecer una correspondencia biunívoca entre segmentos fónicos y contenidos, tal como exige un planteamiento estrictamente estructural'. Fenómenos como la alomorfia (segmentos fónicos distintos correspondientes -en contextos diferentes - a un mismo significado), la amalgama (una única secuencia que remite de manera conjunta a más de un significado) o la homonimia (segmentos idénticos que expresan contenidos diferentes) plantean serias dificultades a esta interpretación. De los tres, es la amalgama el que más atención ha recibido al alterar de forma directa, en un contexto concreto, la relación uno a uno entre significante y significado. Dentro de los marcos basados en la segmentación interna de la palabra, podemos distinguir dos tipos de acercamientos que intentan evitar la amalgama a partir de presupuestos y procedimientos muy diferentes.

El primero de ellos trata de compatibilizar la naturaleza fonemática del significante del signo mínimo con una interpretación sígnica de las categorías morfológicas. El resultado es un análisis en el que se fuerza la segmentación de la palabra con el fin de establecer relaciones uno a uno entre significantes (fónicos) y significados y eliminar, por tanto, cualquier situación de amalgama. Para que la segmentación sea posible, no obstante, es necesario explotar otro fenómeno que algunos autores consideran igualmente conflictivo: el morfo cero. La aproximación obtiene resultados descriptivos perfectamente aceptables en ciertos dominios. En otros, sin embargo, y a medida que las situaciones de amalgama son más complejas, la aplicación exhaustiva de la técnica de la segmentación conduce a resultados arbitrarios. En esta línea pueden ser situadas propuestas descriptivas como la de Stockwell, Bowen \& Martin (1965) seguidos por Marcos Marín (1980)— o la de Álvarez, Monteagudo \& Regueira (1986) en sus análisis de las conjugaciones española y gallega respectivamente. En ambos casos se ponen límites a la segmentación y se reconoce la expresión amalgamada de las categorías de número y persona, por una parte, y de tiempo, modo y aspecto por otra.

La situación es muy distinta en Martínez (1977). Para evitar la amalgama no se fuerza, como en el caso anterior, la segmentación de las secuencias fónicas. Uno de los instrumentos que hacía posible esta tarea, el morfo cero, es rechazado explícitamente. La segmentación se circunscribe, pues, a los límites en que sea posible llevarla a cabo sin hacer uso de elementos vacíos. Cuando el

6. La interdependencia entre los planos de la expresión y del contenido y, en concreto, la biunivocidad entre significante y significado, es el postulado estructural del que depende el llamado principio de la funcionalidad (Cfr. Coseriu, 1981). Este principio, caracterizador de todas las escuelas estructurales, determina qué hechos se deben considerar como constitutivos de una lengua. Su aplicación al análisis de los datos se realiza mediante la conocida técnica de la conmutación. 
resultado del análisis es una secuencia fónica insegmentable que remite de manera conjunta a más de un contenido, la conclusión es que nos encontramos ante un único significante $y$, por tanto, ante un único significado: no existe, pues, amalgama alguna. La consecuencia de esto último es que los contenidos identificados, al ser componentes de un mismo significado, poseen naturaleza monoplana: son figuras. Mientras que un planteamiento como el descrito anteriormente obligaba a forzar la segmentación para justificar el carácter sígnico de las categorías morfológicas, Martínez (1977) —como Alarcos (1977, 1978)— está eximido de esa obligación al concebirlas inicialmente como figuras de contenido. Como nota el propio Martínez (1977: 161):

Tanto la noción de «amalgama» como la de «significante» se destinan, parece, a arropar la idea de que el elemento básico de la gramática es el «monema», y su dominio de análisis la «primera articulación».

Frente a esta idea, Martínez asume la concepción hjelmsleviana de la lengua como sistema de figuras, de la expresión y del contenido, que se combinan para formar signos (Cfr. Martínez, 1977: 161-162, o también, para una exposición más detallada, Martínez, 1994: § 1.10).

Esta interpretación, sin embargo, presenta dificultades en mi opinión insalvables. En efecto, la dependencia inmediata de lo fónico, en tanto significante de signo, conduce a una caracterización variable de las categorías morfológicas, unas veces como figuras de contenido (cuando carecen de expresión fónica individualizada) y otras como significados de signo (cuando les corresponde una secuencia específica). Para Martínez, esto no es un problema7:

[La gramática] operará exclusivamente en términos de morfemas (figuras de contenido), aunque - eventualmente y según los contextos - algunas de estas figuras funcionen como significados de monema [=signo mínimo]. Una gramática así considerará en principio irrelevantes hechos como que un mismo morfema (por ej. 'masc.') sea unas veces figura (en gato, por ej.) y otras significado (como en gatos); o que, de dos morfemas de un mismo paradigma (por ej., 'sing.' / 'plur.'), uno sea figura ('sing.' en perro) y el otro signilicado ('plur.' en perros) [...] (Martínez, 1977: 162)".

Estas situaciones, que Martínez admite y considera gramaticalmente irrelevantes, pueden ser utilizadas para cuestionar el planteamiento a partir de sus

7 Tampoco para Pena, quien comparte la postura de Martínez: Cfr. Pena (1990: 6, n. 1), (199la: 367) y (199lb: 69, n. 2).

\& Como se puede observar, Martínez maneja morfema en dos sentidos: como figura de contenido, que es el valor que otorga expresamente al término, pero también como contenido categorial (singular, plural, masculino, femenino...) independientemente de su configuración semiótica, lo que le permite afirmar que un mismo morfema puede ser unas veces figura y otras significado. 
consecuencias. En concreto, no es posible oponer, y por tanto integrar en una misma categoría (del tipo que ésta sea), entidades lingüísticas de naturaleza no homogénea. La identidad semiótica entre los elementos integrantes de una oposición paradigmática es condición previa y necesaria para el establecimiento de la misma. Aceptar la posibilidad de que «de dos morfemas de un mismo paradigma uno sea figura y el otro significado» constituye una violación expresa de este principio estructural que encuentra aquí una excepción injustificada.

El análisis de los resultados de la perspectiva adoptada por Martínez (1976) hace rechazable su propuesta, cuyos defectos, por otra parte, hay que buscar en sus premisas: de manera inmediata, en la concepción fónica del significante del signo mínimo, ya que es la existencia o no de segmentos específicos la que determina la naturaleza semiótica, variable, de las unidades del contenido. En una perspectiva más general, tanto esta visión del significante como sus consecuencias en el plano del contenido encuentran su justificación en una interpretación - a mi juicio, inadecuadamente reductiva- de los signos lingüísticos como agregados de figuras.

Además de su ineficaz respuesta a la amalgama, ninguna de las propuestas comentadas hasta ahora aborda los problemas originados por la alomorfia y la homonimia. Su preocupación esencial es, por tanto, el mantenimiento de la relación uno a uno entre significante (fónico) y significado en cada contexto concreto.

Frente a este tipo de planteamientos, existe la posibilidad de renunciar a la asociación directa entre significados y secuencias fónicas para incidir exclusivamente en el carácter distintivo de estas últimas. Martinet, por ejemplo, afirma:

En cuanto al monema [= signo mínimo], no postulamos en modo alguno que se manifieste siempre y necesariamente como un segmento distinto del enunciado, sino sencillamente que se corresponde, en el enunciado, a una diferencia formal [...] (Martinet, 1985: 45)".

Martinet se limita de este modo a reconocer la posibilidad de la amalgama, pero no responde a las interrogantes teóricas que estas situaciones plantean a modelos, como el suyo, en los que el significante del signo mínimo está integrado por fonemas.

El reconocimiento de la expresión conjunta de las categorías verbales en lenguas como el español constituye uno de los puntos de partida de los trabajos

Y a continuación critica expresamente los dos tipos de acercamiento que han sido expuestos:Si se quiere hacer coincidir necesariamente todo significado con un segmento distinto, se ve uno abocado o bien a segmentaciones absolutamente arbitrarias, como sería en rosarum atribuir, por ejemplo, el segmento ros- al morfema de significado «rosa», el segmento - ar-a un morfema de genitivo y el segmento - um a un morfema de plural, o bien a la identificación de un monema único llamado de genitivo-plural (Martinet, 1985: 45). 
de Veiga (Cfr. especialmente 1990 y 1992), quien prescinde de cualquier intento de segmentación fónica de la palabra y adopta una perspectiva inscribible en el modelo de palabra y paradigma. Con la asunción explícita de una metodología estructural y funcional, Veiga conmuta contenidos potencialmente adscribibles a los dominios categoriales que le interesan y comprueba la existencia de cualquier tipo de cambio en la expresión fónica de la palabra, considerada ésta como un todo. Los resultados descriptivos son, desde luego, sobresalientes y hacen de la propuesta de Veiga la descripción más completa que existe del sistema de oposiciones del verbo español.

Si nos dirigimos, sin embargo, hacia la concepción morfológica asumida por el autor, ésta se encuentra inespecificada en relación con dos de los aspectos que nos interesan. Por una parte, Veiga se refiere siempre a tiempo y modo como categorias gramaticales sin concretar si se trata de signos, significados o figuras. Para sus objetivos, basta con que se trate de entidades funcionales. Más allá de ello, su planteamiento es compatible con cualquiera de estas opciones, siempre en función del segundo punto de interés, también abierto: el preciso papel de lo fónico en relación a las categorías. A la hora de conmutar contenidos las repercusiones que Veiga busca en el plano de la expresión son exclusivamente fónicas (Veiga, 1992: 164, n. 3), pero el estatuto formal (significante) o sustancial de la palabra fonológica respecto de los valores gramaticales es algo que no se aclara o, más aún, que no interesa: la elaboración teórica y metodológica se encuentra fuertemente condicionada por el objetivo descriptivo y se reduce al mínimo necesario para alcanzarlo con éxito.

En definitiva, las implicaciones y posibilidades teóricas de la adopción del modelo de palabra y paradigma no son planteadas. O se reconoce, simplemente, su necesidad (al menos, en algunos dominios) o su aplicación - y rentabilidad- descriptiva oscurece cualquier otro tipo de consideración teórica.

\subsection{El significante no (exclusivamente) fónico del signo mínimo}

\subsubsection{La ampliación del significante en el léxico y la sintaxis}

Frente a la interpretación restrictiva del concepto de expresión realizada por Hjelmslev (1943) —Cfr. Rojo, 1979: 114-117—, algunos autores han mostrado la necesidad de superar, con carácter general, la identificación entre unidades del plano de la expresión y fonemas. Ningún principio teórico puede argüirse a favor de esta equivalencia cuando el plano de la expresión se define tan solo por su interdependencia con el plano del contenido. Trujillo propuso así distinguir entre expresión y significante. La expresión se reduce a lo fónico en correspondencia con el valor efectivo - y no las posibilidades teóricas- que le atribuye Hjelmslev (1943). El significante, por su parte, se define en exclusiva por su 
asociación necesaria con hechos del otro plano (significado). El concepto de expresión (fónica) se complementa, pues,

con la idea de significante - en el cual cabe no sólo lo exclusivamente fónico, sino también lo semántico y lo puramente distributivo, en el sentido de repartición automática de signos en un orden determinado- (Trujillo, 1976: 161).

Empleando argumentos positivos, además, la interpretación amplia del significante se convierte en una necesidad si se quiere solucionar algunos de los problemas planteados en el léxico (p.e. la homonimia) o, muy especialmente, si se desea conceder a la sintaxis la entidad que la glosemática le negaba. La propuesta de Trujillo, aplicada ya en origen a ambos dominios, fue retomada, modificada y rentabilizada por autores como Rojo (1979), en su tratamiento del concepto de función sintáctica, o Gutiérrez, quien la aplica, además de a la sintaxis (1983), a la determinación de distinciones léxicas en los casos de homonimia (1981, 1989).

Conviene insistir en que el planteamiento, al menos en el léxico y tal y como lo desarrollan Trujillo y Gutiérrez, no supone la negación de la función significante de lo fónico, sino la negación de que esta función le corresponda siempre y/o en exclusiva. Como señala Trujillo, significante y expresión no son cosas que pueden identificarse absolutamente: el significante puede estar sólo en la expresión, pero puede también incorporar componentes semánticos [...], o estar, incluso, compuesto exclusivamente de elementos semánticos (Trujillo, 1976: 98).

Igualmente, Gutiérrez, siguiendo muy de cerca a Trujillo, simboliza en la expresión Significante $= \pm E(x p r e s i o ́ n) \pm P$ la distinción entre «expresión, secuencia de elementos fonológicos, y significante, que incluye la expresión (si existe) más otros factores (de valor y de valencia)» (Gutiérrez, 1981: 157), recogidos estos últimos bajo la notación $P$. Existen, por tanto, tres posibilidades en cuanto a la composición del significante ${ }^{10}$ : Significante $=E$, Significante $=E+$ $P$, Significante $=P$.

1) Como se ve, Trujillo, y a partir de él Gutiérrez, utilizan expresión en un scntido restringido (= lo fónico) de acuerdo con la utilización real que hace del mismo Hjelmslev (1943). Creo, sin embargo, que resulta más útil emplearlo en un sentido amplio, en consonancia con su valor como designación de uno de los planos lingüísticos (el de la expresión) por oposición al otro (el del contenido), posibilidad ésta por la que el propio Trujillo podría haber optado (Cfr. Rojo, 1979: 117). De este modo, poseemos un término general (expresión) en el que podemos incluir figuras (p.e. fonemas), asociaciones de éstas en cadenas (sílabas, morfos, etc.), constituyentes de signos en relación de interdependencia con significados (significantes), etc., caracterizables en conjunto por su oposición a las entidades (todas contenidos) del otro plano. A lo largo de todo el trabajo (salvo cuando, como en este caso, se citen expresamente las opiniones y terminologías propuestas por los autores) expresión y contenido son usados con este valor. La fórmula anterior de Gutiérrez puede ser reescrita, entonces, como Significante $= \pm$ Expresión fónica \pm Expresión no fónica. 


\subsubsection{La ampliación del significante en morfología}

Aunque en el nivel del signo mínimo lo más frecuente es la identificación entre significante y segmento fónico, diversos autores han realizado propuestas de ruptura de tal equivalencia. Algunas se han dirigido hacia una ampliación del significante. Otras, más radicales, han negado directamente que los elementos fónicos constituyan, ni siquiera parcialmente, el significante de los signos mínimos.

\subsubsection{El significante no exclusivamente fónico}

En un artículo escrito en 1937 y publicado póstumamente (1945), Whorf critica que el reconocimiento de categorías gramaticales ${ }^{11}$ en una lengua se restrinja a los casos en los que éstas aparecen expresadas por medio de morfemas (= segmentos fónicos asociados con contenidos). Una actuación de este tipo resulta inadecuadamente restrictiva puesto que, en opinión de Whorf, existen otros medios a través de los cuales se puede marcar la presencia de una categoría gramatical:

The mark need not be part of the same word to which the category may be said to be attached in a paradigmatic sense; i.e. it need not be a suffix, prefix, vowel change, or other «inflection», but may be a detached word or a certain patterning of the whole sentence (Id: 88).

Una vez ampliado así el rango de procedimientos que pueden ser considerados significantes gramaticales, Whorf diferencia entre categorías manifiestas (overt categories), también llamadas fenotipos, y categorías encubiertas (covert categories) o criptotipos. Ahora bien, la ampliación del concepto de marca es previa a esta dicotomía. Frente a la interpretación realizada por algunos autores (p.e. Moreno Cabrera, 1991: 168-169), la distinción de Whorf entre categorías manifiestas y categorías encubiertas no tiene que ver con el tipo de marca a través del cual éstas se expresan (afijal vs. no afijal), sino con el hecho de que la misma (sea o no afijal) está presente -o no- en todos los tipos de enunciados en los que la categoría puede aparecer ${ }^{12}$. De acuerdo con las caracterizaciones de Whorf,

An overt category is a category having a formal mark which is present (with only infrequent exceptions) in every sentence containing a member of the category (Id: 88).

11 Concepto que en Whorf recubre no solo nuestras categorías morfológicas sino también las clases de palabras.

12 Aunque sí es cierto que en principio sólo pueden aspirar a ser totalmente manifiestas (= manifiestas en cualquier contexto) aquellas categorias expresadas en el interior de la palabra por medio de diferencias fónicas. 
A covert category is marked, whether morphemically or by sentencepattern, only in certain types of sentence and not in every sentence in which a word or element belonging to the category occurs (Id: 89) ${ }^{13}$.

Los ejemplos de marca proporcionados por Whorf son heterogéneos y abarcan cualquier hecho a través del cual se pueda deducir la presencia de un determinado valor categorial. El plural, por ejemplo, puede ser expresado en inglés por medio de un afijo (cats); pero también mediante la ausencia del artículo (fish appeared), la utilización de un adjetivo "pluralizante» (the fish will be plentiful), la combinación entre el artículo definido y la ausencia de una marca «singularizante» de persona (the Chinese arrived), etc. (Cfr. Id: 88).

Es importante recalcar que para Whorf todas las categorías, encubiertas o manifiestas, y sea cual sea el modo de manifestación de estas últimas, poseen el mismo valor gramatical. El encubrimiento no supone menor sistematicidad en la organización interna de la categoría ni menor contribución al diseño gramatical global de la lengua.

Una concepción también ampliada del significante de las categorías morfológicas, aunque con muchas más restricciones que la presentada por Whorf, la podemos encontrar en una obra clásica: el estudio del sistema aspecto-temporal del griego antiguo realizado por Sánchez Ruipérez (1954). Para éste,

Dentro de una palabra, morfema es el significante de una categoría gramatical [...]. Así, en lat. legollegis uoluoluoluis, -o es un morfema, -is es otro morfema. Al incluir en la definición «dentro de una palabra» se excluyen los elementos sintácticos significativos (Sánchez Ruipérez, 1954: 12).

13. De acuerdo con estas descripciones se puede decir que una categoría manifiesta es la que tiende a serlo siempre, mientras que una categoría encubierta es la que sólo aparece marcada (se manifiesta expresivamente) en ciertos tipos de contextos. De manera inmediata, por tanto, nos encontramos ante ocurrencias manifiestas y ocurrencias encubiertas de una categoría. Por ejemplo, el plural inglés es manifiesto en The boys (expresión afijal en el sustantivo), también en The sheep sleep (expresión por medio de la forma verbal), pero está encubierto en The sheep slept (donde singular y plural son indistinguibles). No obstante, y a partir del análisis de las ocurrencias concretas, Whorf atribuye a una categoría carácter fenotípico o criptotípico en su conjunto (y éste es el sentido en que utiliza los conceptos en su trabajo) de acuerdo con el carácter dominante de los casos de manifestación o de encubrimiento. Desde este punto de vista, el plural se considera en inglés un fenotipo puesto que son claramente mayoritarios los casos en los que se manifiesta mediante una marca explícita. Los casos minoritarios en una u otra dirección no menoscaban, según Whorf, la naturaleza manifiesta o encubierta de una categoría (Cfr. Id: 89 , n. 2). De todos modos, y aunque Whorf no lo considera, la base cuantitativa de la caracterización posibilita la existencia de grados en los que una categoría puede ser manifiesta o encubierta.

Por otra parte, Whorf maneja también los términos manifiesto y encubierto, de forma circunstancial y sin advertencia explícita, en relación con el plano del contenido. Una categoría encubierta es, en este sentido, aquella que no refleja distinciones naturales (ontológicas) sino puramente culturales (referencialmente opacas). Así, categorías expresivamente encubiertas, como el género en inglés o en navajo, son también criptotipos desde el punto de vista del contenido. 
Así pues, el morfema, de carácter fónico, es para Sánchez Ruipérez una parte del significante de las categorías gramaticales. La otra parte, «los elementos sintácticos significativos», se revela en toda su importancia en los casos de sincretismo, o, con el término utilizado por el autor, de coincidencia. Frente a la neutralización, que «ha de contar con una explicación en el plano del significado» (Id: 30), la coincidencia supone mera identidad externa, fónica, entre unidades. En esta situación se hallan, por ejemplo, el nominativo y el acusativo plurales en la tercera declinación latina (consules), a diferencia de lo que sucede en la segunda (equi vs. equos). En casos como éste, señala Sánchez Ruipérez,

La separación de los significados, que no están neutralizados, sino que están potencialmente distintos, es realizada por factores sintagmáticos, Ios cuales han de ser considerados como parte del significante. Así sucede en [...] consules (consules creantur, boni consules / cupit consules uidere, bonos consules) (Id: 30$)$.

Para este autor, sin embargo, la importancia relativa de los factores fonológicos y sintagmáticos es distinta en cada dominio categorial. En uno de los extremos se sitúa la categoría de caso. Los fenómenos de rección permiten identificar los miembros de esta categoría tornando redundantes las diferencias fónicas y permitiendo la aparición, por tanto, de hechos de coincidencia. Es lo que sucede con el dativo y el ablativo plurales en latín clásico. Su identidad fonémica en todas las declinaciones no es prueba, según Sánchez Ruipérez, de su neutralización:

La distinción formal de uno y otro caso en el singular [...] ha establecido unas relaciones sintagmáticas, las cuales han mantenido ambos casos bien diferenciados en el plural (v. gr. nocere feminae, egere femin, nocere feminis dat., egere feminis ablat.). Precisamente esta posibilidad de determinación sintagmática de la noción casual es la condición previa necesaria para este sincretismo de casos (Id: 30-31).

De lo manifestado por el autor se debería extraer, lógicamente, la prioridad teórica y descriptiva de los hechos sintagmáticos sobre los fonológicos en la identificación y análisis de las categorías que respondan a este tipo de comportamiento. Si aceptamos la posición mantenida por el autor, esto es, que la rección permite diferenciar a dativo y ablativo en el plural a pesar de su homonimia, la misma rección debe ser suficiente para diferenciarlos también en el singular con independencia de que aquí existan al tiempo diferencias fónicas. Las posibilidades sintagmáticas son constantes mientras que los hechos fónicos pueden, precisamente por la existencia y generalidad de aquéllas (Cfr. la cita anterior), estar ausentes. Su presencia es, por tanto, redundante. De todo ello se debería concluir que en situaciones de convivencia entre factores fónicos y 
sintagmáticos son estos últimos los auténticamente pertinentes a la hora de describir el significante.

Sin embargo, Sánchez Ruipérez no desarrolla de este modo sus opiniones. Por un lado, como sucede con buena parte de los autores que proponen una ampliación del significante en el léxico y la morfología, porque a lo sintagmático sólo se acude cuando lo fónico resulta evidentemente insuficiente, cuando es necesario ofrecer argumentos que permitan justificar una distinción de unidades en casos de identidad fónica. Más allá de las situaciones de homonimia, lo sintagmático suele ser ignorado, olvidándose de este modo el valor definitorio que previamente, y al menos en determinadas ocasiones, se le ha otorgado.

En el caso que nos ocupa existe también un segundo motivo, inmediato, que lleva al autor a no explotar la dimensión sintagmática del significante mediante el que se expresan las categorías. Para Sánchez Ruipérez, su objeto concreto de estudio, el tiempo y el aspecto, se sitúa en el extremo opuesto al caso: su significante es exclusivamente fónico. En relación con el aspecto, señala explícitamente:

[la coincidencia] no puede existir en el sistema de aspectos, v. gr., pues las nociones aspectuales son semánticas, contienen una descripción del modo de producirse la acción verbal, son independientes de toda relación sintagmática (Id: 31$)^{14}$.

Así pues, y dependiendo de la categoría expresada, el significante de los signos mínimos tiene, según Sánchez Ruipérez, una composición diferente. Puede estar integrado en exclusiva por elementos fónicos (entre otras posibilidades, cuando los significados son aspectuales), por éstos combinados con hechos sintagmáticos que trascienden el ámbito de la palabra (en las oposiciones casuales, por ejemplo) o por rasgos sintagmáticos en exclusiva (como sucede con algunas oposiciones de caso en determinadas circunstancias).

\subsubsection{El significante exclusivamente no fónico}

A diferencia de este tipo de planteamientos, centrados en una ampliación del significante del signo mínimo, otros autores han optado por una negación explícita de la relación compositiva entre significantes y fonemas. Hockett, por ejemplo, en un denso y ambicioso trabajo (1961), intenta demostrar lo inade-

14 El carácter «semántico» no puede aducirse como justificación (o, cuando menos, como única justificación) de la imposibilidad de sincretismos en el aspecto. Tan semántica —o intrínseca (Cfr. 1954: 9) - es la descripción aportada por el aspecto como lo pueda ser la del número, al que, en cambio, sí se concedió la posibilidad de estar parcialmente distinguido mediante un hecho sintagmático como la concordancia. 
cuado de las propuestas que conciben al morfema (= significante del signo mínimo ${ }^{15}$ ) como compuesto de fonemas. Para ello, insiste en las consecuencias, nunca aceptadas, de esta postura: en concreto, la necesidad de reconocer un morfema distinto siempre que su constitución fónica sea diferente. Son los hechos de alomorfia, por tanto, los que Hockett enarbola como principal argumento empírico en contra de la relación constitutiva fonema-morfema. Tomando como ejemplo la oposición entre knife y knives en inglés, Hockett señala cómo la defensa de dos cualesquiera de los asertos siguientes provoca necesariamente la negación del tercero (Cfr. Hockett, 1961: 30):

(1) Knife y knive-son el mismo morfema.

(2) Knife y knive-son fonémicamente distintos.

(3) Un morfema se compone de fonemas.

Puesto que nadie parece dispuesto a negar la veracidad de (1) ni la de (2), es (3) el más firme candidato a ser rechazado. Hockett da cuenta de la existencia de dos vías a través de las cuales se intenta mantener, si bien de forma indirecta, la veracidad de (3) sin por ello negar las afirmaciones que la acompañan.

La primera alternativa consiste en el diseño de lo que Hockett llama un sistema pseudo-fonológico, integrado por morfofonemas ${ }^{16}$. Los morfemas se componen de morfofonemas y, éstos, a su vez, son realizados por medio de fonemas. La ventaja del acercamiento es que relega la variabilidad al nivel de la realización de los morfofonemas. Knife y knive-pueden ser considerados el mismo morfema porque su constitución morfofonológica es idéntica, aunque la realización fonológica del último de sus morfofonemas, representable como ${ }^{\mathrm{m} /}$ F/, sea distinta: /f/ en un caso y /v/ en el otro. La relación de composición entre morfemas y fonemas es sustituida, pues, por dos relaciones con una unidad intermedia como eje: una de composición (C), que liga morfemas y morfofonemas, $y$ otra de realización $(R)$, que une los morfofonemas con los fonemas.

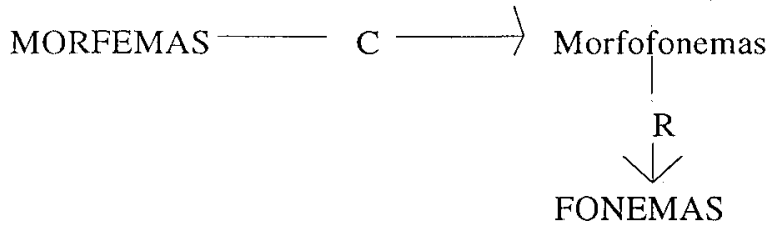

15 Lo cierto es que no está claro si Hockett Ilama morfema al signo mínimo o sólo a su significante. Dado que se tratan las relaciones entre morfema y fonemas, prefiero interpretar que por morfema se entiende el significante del signo, ya que no es defendible que sea el signo en su conjunto el que se relaciona (por composición, realización o proyección) con los fonemas. Ésta sería, pues, la primera crítica que habría que realizar si Hockett emplease el término morfema para designar el signo mínimo.

16 El primer tratamiento amplio publicado al respecto es, según Hockett, el de Swadesh \& Voegelin (1939). 
La segunda opción es similar pero simétrica. Se acude a un sistema pseudomorfémico cuyas unidades, los morfos, constituyen la realización de los morfemas $^{17}$. Son los morfos los que, ya sin dificultades, se componen de fonemas. La situación es ahora:

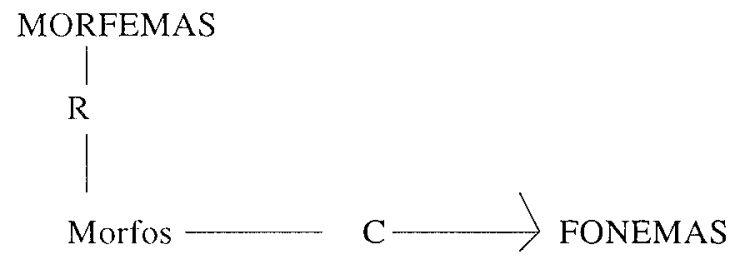

Hockett considera legítimos los dos métodos descriptivos. Ambos podrán ser utilizados, incluso de forma encadenada, en función del tipo de lengua o el hecho concreto que se analice (Cfr. Id: 34-35). Resulta claro, en cualquier caso, que estas alternativas no alteran la constatación inicial de que el morfema no se compone de fonemas. Para reforzar su postura y demostrar de forma definitiva la inexistencia de cualquier tipo de relación compositiva, siquiera indirecta, entre morfema y fonema, Hockett da un paso más y niega la realidad empírica, aunque no la utilidad descriptiva, de morfos y morfofonemas: se trata de meros «artifacts of analysis», «conveniences for description» (Id: 42). Cuestionada la entidad real de las unidades que sirven de puente entre morfema y fonema, las relaciones compositivas que éstas fundamentan carecen también de justificación.

De acuerdo con la hipótesis de la dualidad defendida por Hockett, existen en las lenguas dos grandes sistemas o estratos: el gramatical y el fonológico. Cada uno de ellos está integrado por una serie de unidades de diferente tamaño que mantienen entre sí relaciones de composición. La argumentación de Hockett sobre la falta de entidad empírica de morfo y morfofonema se apoya en las dificultades para integrar a ambas unidades en los sistemas fonológico y gramatical, respectivamente, sin provocar desajustes en ellos. Dado que es ésta la unidad que presenta mayor interés, me centraré en el análisis de los comentarios que Hockett realiza a propósito del morfo.

El estrato fonológico está integrado, en opinión de Hockett, por las siguientes unidades, cada una de las cuales está compuesta por una o más de las situadas a la derecha:

17 Hockett cita a Harris (1942) como la primera presentación detallada de esta alternativa. El término morfo lo introduce el propio Hockett en (1947). 


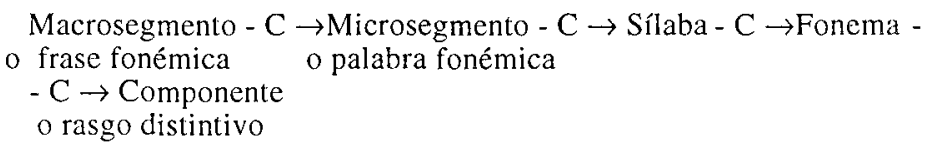

Aunque, según este autor, se puede discutir la necesidad de añadir alguna otra unidad en esta escala, lo indudable es que la inclusión del morfo provocaría serios desajustes. Hockett menciona dos casos:

a) Sílaba y morfo son incompatibles en la jerarquía: en ninguno de los dos sentidos morfo $\rightarrow$ sílaba ni sílaba $\rightarrow$ morfo es defendible una relación de composición.

b) Existen casos, incluso, en los que un morfo es menor que un fonema. Así, por ejemplo, en el verbo inglés /ju:z/ (frente al sustantivo/ju:s/) existe un morfo compuesto por el rasgo distintivo sonoridad. La posición del morfo, por tanto, también plantea problemas en relación con el fonema y el rasgo distintivo.

La conclusión es que:

Morphs, then, do not fit neatly into the hierarchical patterning of phonology, but stand to it in a sort of syncopated counterpoint. This is a clear mark of their special nature as intervening variables, rather than as basic linguistic elements; they are a descriptive convenience, not an empirical necessity (Hockett, 1961: 37).

Dicho de otro modo, el morfo es una unidad de la lingüística pero no una unidad del lenguaje. Este segundo nivel de la propuesta de Hockett, la negación de la realidad empírica de la entidad morfo, resulta en mi opinión poco acertada. Por una parte, los argumentos aportados son altamente insuficientes. La posición del morfo respecto del fonema, por ejemplo, no plantea a mi modo de ver dificultades. Un morfo nunca está inmediatamente compuesto por rasgos distintivos. Si vemos la necesidad de identificar un segundo morfo en /ju:z/ éste debe estar constituido por el fonema /z/ y no por la sonoridad ${ }^{18}$. La sonoridad es el rasgo que, en el nivel siguiente, permite diferenciar al fonema $/ z /$ del fonema $/ \mathrm{s} /$

La otra razón inmediata manejada por Hockett es la incompatibilidad entre la sílaba y el morfo debido a la imposibilidad de establecer relaciones compositivas entre elllos. En ese caso ¿por qué no se prescinde más bien de la sílaba? En realidad, no creo que sea necesario prescindir (al menos, por las razones que se aportan) de ninguna de las dos unidades. Lo que conviene plantear es el porqué de la imposible convivencia de ambas: ¿por qué son definitorias las relaciones de composición en cada estrato hasta el punto de impedir la consideración de

is En todo caso, lo discutible no es que los morfos se compongan de fonemas, sino que a cada morfema haya de corresponder necesariamente un morfo distinto. 
unidades que no encajan en una sucesión lineal ordenada por tamaños?, ¿por qué no se acepta la existencia de distintos tipos de elementos fonológicos? $\mathrm{O}$, si se admite que sólo son «estrictamente» fonológicas las unidades que ocupan una posición en la escala, ¿por qué no pueden existir unidades, fonológicas también, aunque diferentes a las anteriores, fuera de ese estrato?

Sin ninguna duda los morfos son una unidad puente entre la gramática y la fonología. Como el propio Hockett reconoce, «They are phonological elements, by definition; but they are not determined purely by phonological criteria» (Id: 37). Sin embargo, ello no tiene por qué constituir evidencia de la entidad meramente descriptiva del morfo, salvo que, como es el caso, se maneje una determinada preconcepción de la estructura de las lenguas y la naturaleza de sus unidades. Invirtiendo el planteamiento, es en mi opinión la realidad empírica del morfo la que - sumada a otros argumentos - prueba la necesidad de someter a revisión la concepción de los sistemas lingüísticos defendida por Hockett (1961).

Pero además, y por otra parte, cabe examinar también los efectos de la eliminación del morfo del inventario de unidades del lenguaje: ¿cómo se puede dar cuenta en el plano empírico, ya no en el descriptivo, de la relación entre el morfema y los fonemas? La alternativa a este respecto es de un nominalismo extremo: Hockett se limita a decir que entre las unidades del estrato gramatical y las unidades del sistema fonológico existe una relación de proyección (P). El morfema, pues, se proyecta en («is programmed into» o «is mapped into») fonemas.

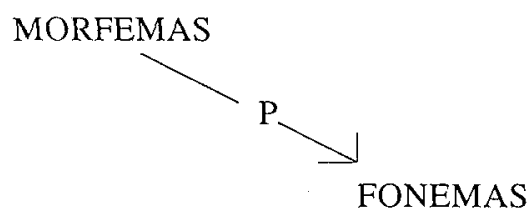

La naturaleza exacta de esta relación (diferente de la relación de realización (R), eliminada con la supresión empírica de las unidades que la justificaban) no se aclara. Desde luego, yo no advierto una mayor cercanía de la propuesta de Hockett a los hechos reales y no reconozco en ella pruebas de que, en relación al morfo, la rentabilidad descriptiva de éste no corra pareja a su realidad empírica.

Otra línea de ruptura de la identificación entre significante de signo mínimo y secuencia fónica está representada, ahora en la linguiística española, por los trabajos de Fernández Pérez (Cfr., en especial, 1991 y 1993). Para esta autora, el morfema (= signo mínimo) posee un significante no fónico. Como entidad formal que es, el significante no puede ser identificado con las realizaciones sustanciales a través de las que se manifiesta. Ahora bien, y éste es el paso que 
caracteriza la propuesta de Fernández Pérez, al significante del morfema se le asigna una naturaleza sintagmática, un valor constructivo. En consecuencia, son hechos de este tipo, y no fónicos, los que constituyen su manifestación sustancial. Los efectos y diferencias fónicas pueden también coexistir, como medio de realización, con los hechos de combinatoria, pero poseen un carácter redundante. Así, ya en (1986) y ocupándose de la delimitación de la gramática, Fernández Pérez afirma:

Desde nuestra perspectiva [...] la Gramática se ocupa del significante del signo; es decir, de significantes asociados a contenidos. No se trata, así, de significantes sonoros, sino de significantes manifestados por concordancias, orden, flexión, etc. (Fernández Pérez, 1986: 21).

Esta visión ha sido posteriormente desarrollada en una serie de trabajos en los que los morfemas, en consonancia con las opiniones anteriores, se conciben como:

Unidades con incidencia construccional, táctica, lo que confirma su valor gramatical y la presencia de un significante no-fónico: se trata de signos mínimos que repercuten en la combinatoria y en la capacidad relacional de las unidades sintácticas (palabras, frases, cláusulas y oraciones) (Fernández Pérez, 1991: 62).

Por tanto, la vía metodológica de identificación de estas entidades no consiste en la comprobación de correspondencias entre contenidos y segmentos o alteraciones de tipo fónico, sino en:

Prestar atención a marcas sustanciales como la concordancia o la «cosecutio» indicadoras de los morfemas que facilitan la relación y combinatoria entre unidades sintácticas (Fernández Pérez, 1991: 62-63).

En el planteamiento de Fernández Pérez, la existencia de un significante de naturaleza sintagmática, no fónica, es condición necesaria para que se pueda hablar de morfema. Al tiempo, la unidad morfema es el vehículo exclusivo a través del cual se realizan en las lenguas las categorías morfológicas. Significante no fónico, morfema y categoría morfológica quedan de este modo fuertemente asociados. La autora expone con claridad lo que ello implica:

$\mathrm{Ni}$ «morfemas léxicos» ni «morfemas derivativos» pueden verse como signos dado que no resulta factible hallar significantes no-fónicos que se asocien a los contenidos. No estamos, pues, ante morfemas - si queremos mantener la concepción del morfema como signo-, de la misma manera que tampoco estamos ante entidades que hayan de interesar a la Gramática; el tipo de morfemas con carácter sígnico, y por tanto unidades indudablemente 
gramaticales, es el que corresponde a los denominados «morfemas flexivos» (Fernández Pérez, 1991: 62). ${ }^{19}$

A mi modo de ver, sin embargo, de la inexistencia de un significante sintagmático en los elementos léxicos y derivativos no se debe concluir la naturaleza no sígnica de los mismos. Considerar en todos los casos anteriores la presencia de entidades biplanas no tiene por qué impedir el establecimiento de una clara diferenciación entre las que, de acuerdo con una determinada concepción de la gramática, de índole construccional, se estiman como objeto de estudio de la misma y las que, por falta de incidencia sintáctica, son excluidas. Parece más conveniente, por tanto, hablar de morfemas en los tres casos, si bien con caracteres adicionales muy distintos.

Mi postura, además, es en cierta medida la inversa a la sostenida por Fernández Pérez: mientras que los fenómenos de combinatoria sintáctica caracterizan en parte a las unidades léxicas ${ }^{20}$ (piénsese en la valencia), hechos como las concordancias son externos a los morfemas flexivos y no pueden ser utilizados, por tanto, para definirlos (aunque, sí, como veremos, para identificarlos). Intentaré mostrar, por tanto, en relación a las categorías morfológicas:

a) que lo fónico es esencial para determinar su existencia y que, en realidad, son las diferencias fónicas (aunque no necesariamente segmentos fónicos específicos) las que justifican el reconocimiento de unidades morfológicas distintas incluso cuando se recurre a su combinatoria;

b) que lo sintagmático ( $y$, en concreto, el tipo de fenómenos habitualmente señalados) no puede ser considerados como significante, ni sus manifestaciones como sustancia del significante.

Para ilustrar los puntos anteriores acudiré a hechos incuestionables en sí mismos: la categorialidad del número en español y la existencia en esta misma lengua de concordancia en número entre, por ejemplo, sustantivos y adjetivos. La concordancia es, además, el ejemplo prototípico de implicación sintagmática para Fernández Pérez, por lo que la exposición de los problemas en los casos más claros, como éste, debe servir como crítica del acercamiento en general. La pregunta concreta es: $\measuredangle$ constituye la concordancia un procedimiento sustancial suficiente para reconocer la existencia de la categoría de número en español?

De acuerdo con el planteamiento de Fernández Pérez, «son las repercusiones sintácticas que comprobamos a través de las concordancias las que nos indican la singularidad y la pluralidad lingüísticas» (1993: 58). De este modo, vaso o

19 Lo cual no quiere decir, sin embargo, que se dé por supuesto que el ámbito extensivo de los morfemas (flexivos) coincide con el inventario de los mismos habitualmente aceptado (Cfr. 1991: 64).

20 Sin que por ello deban considerarse parte integrante de su significante. No es éste el momento, sin embargo, de entrar en una crítica del concepto de significante no fónico en el léxico tal como Io entienden Trujillo (1976) o Gutiérrez (1981, 1989). 
sillón, por ejemplo, no son singulares por las diferencias fónicas que presentan frente a vasos y sillones respectivamente, sino por su diferente sintagmática:
(1) Vaso (sing.) vacio (sing.)
(2) Sillón (sing.) vacio (sing.)
*Vaso (sing.) vacíos (pl.)
* Sillón (sing.) vacios (pl.)

El principal punto de apoyo del acercamiento en el nivel descriptivo se encuentra en los casos en los que existe identidad fonológica entre los dos miembros de una oposición categorial. Lo sintagmático revela aquí todo su poder discriminador:

(3) (a) Crisis (sing.) importante (sing.) (b)Crisis(pl.) importantes (pl.)

Sabemos, pues, que crisis es singular en (3a) y plural en (3b) porque concuerda con importante en el primer caso y con importantes en el segundo. Ahora bien: ¿cómo sabemos que estas dos últimas unidades son distintas?, ¿cómo sabemos que importante es singular e importantes plural? Volver ahora los ojos hacia el término regente no sirve de ayuda. Es necesario concluir, por tanto, que la manifestación sustancial que en el plano de la expresión informa de la existencia de dos unidades diferentes, singular y plural, es la fónica (en este caso bajo la forma de presencia/ausencia de /-s/). Lo mismo debe ser dicho de los casos (1) y (2). Se puede prescindir en un principio de las diferencias fónicas en los sustantivos recurriendo a su combinatoria con distintos adjetivos (vaso es distinto de vasos porque concuerda con vacío y no con vacíos), pero la justificación de la diferencia de estos últimos no se puede hacer descansar ya sobre otras realizaciones que las fónicas, a menos, claro, que se caiga en una circularidad estéril (vacio es distinto de vacíos porque concuerda con vaso y no con vasos). La concordancia permite trasladar las distinciones fónicas a otro punto (aquí, del sustantivo al adjetivo), pero no puede finalmente evitarlas. Una vez que se reconoce que los adjetivos se diferencian por su constitución fonológica no queda más remedio que admitir que lo mismo sucede con los sustantivos.

Por lo que respecta a crisis, es cierto que la combinatoria (crisis importante vs. crisis importantes) nos permite reconocer que estamos ante dos unidades distintas homónimas, una singular y otra plural, pero sólo porque:

a) existen casos (como el señalado) en el que los adjetivos están diferenciados fónicamente ${ }^{21}$.

b) existen casos, claramente predominantes, en los que los sustantivos también están diferenciados fónicamente (vaso vs. vasos) ${ }^{22}$. Si todos los sustantivos

21 En este hecho incide Sánchez de las Brozas (1587: 66) al abordar el género: «si no existieran los adjetivos, nadie podría encontrar el género gramatical, y tampoco si los adjetivos tuvieran solamente una terminación».

22 Ésta es, precisamente, la base de la argumentación de Jespersen cuando, en un conocido 
del español fuesen como crisis no se podría defender la existencia de diferencias categoriales en ellos a partir de la combinatoria con diferentes adjetivos. Haccrlo equivaldría, por ejemplo, a sostener que en el sustantivo español también existe tiempo, aunque de expresión fónica homónima e identificación puramente sintagmática: el niño (pres.) come (pres.) vs. el niño (co-pret.) comía $(\text { co-pret. })^{23}$.

Así pues, la concordancia como mecanismo discriminador está subordinada a la diferenciación fónica de los elementos entre los que ésta se establece. Las manifestaciones sustanciales pertinentes (en realidad, las únicas manifestaciones sustanciales) son las fónicas. Ahora bien, conviene no olvidar que se trata de realizaciones sustanciales. La biunivocidad significante-significado es un principio que afecta al nivel formal; entre la forma del significante y su sustancia (fónica), en cambio, las relaciones son más libres, pueden ser multívocas. Eso es lo que sucede con crisis: la misma sustancia del significante /'kRisis/ realiza dos unidades con valores categoriales de número opuestos. En situaciones como ésta la combinatoria puede resultar de ayuda para identificar el valor que debe ser asignado a una unidad. Esta rentabilidad de la combinatoria, sin embargo, no debe llevarnos a atribuirle una función que no le corresponde. Insistiré en ello más adelante.

Si hasta ahora hemos visto que lo fónico constituye la auténtica manifestación sustancial del significante de las categorías morfológicas, examinaremos ahora desde otro punto de vista, de manera directa, por qué fenómenos como la concordancia no pueden ser aceptados como realizaciones de las mismas.

De acuerdo con la visión sintagmática de las categorías morfológicas, lo que constituye su significante son sus posibilidades (restricciones, implicaciones, etc.) combinatorias. No toda ocurrencia de una unidad, claro está, manifiesta sus posibilidades, por lo que la detección de los supuestos rasgos relevantes y definitorios de su expresión debe llevarse a cabo mediante un proceso de catálisis (Cfr. Hjelmslev, 1938: 202; 1943: Cap. XIX). Fundamentar el significante sobre la potencialidad sintáctica plantea, a mi modo de ver, dificultades graves de principio. La función que el significante posee en la lengua, y que éste realiza a través de su sustancia, es la comunicación de un contenido. Las concordancias (o cualquier otro tipo de hechos sintácticos) no siempre están presentes en un enunciado, con lo que en términos prácticos (y la lengua es un objeto práctico, un instrumento) resultan claramente insuficientes como mecanismos

pasaje (1924: 47), identifica en one sheep y en many sheep un singular y un plural respectivamente.

2.3 Un tercer factor, de índole distinta a los anteriores pero necesario también para poder argumentar que crisis es expresión homónima de dos unidades distintas (sing./pl.), es que no cabe hablar de neutralización: no hay combinación con elemento gramatical alguno al que se pueda otorgar el carácter de contexto responsable de la misma. 
discriminadores. Parecen, pues, extraños — por ineficaces - como sustancia de un supuesto significante combinatorio.

Existen, sin embargo, otros argumentos. En (1989) Gutiérrez señalaba dos requisitos que debían reunir todos los hechos a los que se atribuyese valor $P$ como parte del significante de una unidad. Estas condiciones eran: a) ser inmanentes a la lengua, $y$ b) ser susceptibles de contrastación empírica (Cfr. 1989: 48). Gutiérrez, en cambio, no explicita, quizá por juzgarlo obvio, el requisito específico que se ha de exigir. Ser inmanente y observable permiten, de acuerdo con el marco teórico definido, reconocer algo como hecho lingüístico. Pero para que sea significante (tipo especial de hecho lingüístico) ha de satisfacer un requisito más: tener como función propia, inherente, la expresión de un significado, de ese significado del cual aquel hecho se reconoce como significante. Claramente, no es la misión de la concordancia comunicar valores morfológicos. Estamos ante un procedimiento de expresión de valores de otro nivel, sintácticos. A través de la concordancia la sintaxis se sirve de lo morfológico como instrumento, pero lo morfológico posee una entidad propia, se justifica autónomamente en el nivel que le corresponde. La utilización sintáctica de las categorías es posterior, en términos teóricos, a su fundamentación morfológica.

Es necesario insistir, además, en que las categorías morfológicas carecen de valores valenciales, son en sí mismas ajenas a la rección sintáctica. Las relaciones sintagmáticas mantenidas por las categorías morfológicas no trascienden el ámbito de la palabra. En una situación de concordancia del tipo sustantivo-adjetivo no son directamente las categorías morfológicas del sustantivo las que rigen las del adjetivo, sino el sustantivo en su conjunto el que rige al adjetivo, también como entidad unitaria, exigiéndole determinadas propiedades internas ${ }^{24}$. Esto es tenido en cuenta por Fernández Pérez, quien no afirma que los morfemas mantengan relaciones sintácticas sino que «repercuten en la combinatoria y en la capacidad relacional de las unidades sintácticas» (Cfr. supra). Ahora bien, si las relaciones sintácticas son establecidas entre unidades sintácticas (como mínimo, palabras), ni tales relaciones ni sus manifestaciones sustanciales pueden ser consideradas forma o sustancia, respectivamente, del significante de unidades no sintácticas como el morfema ${ }^{25}$. En definitiva, una cosa es que los valores morfológicos condicionen la combinatoria de las unidades sintácticas y otra, en mi opinión no aceptable, que esas restricciones/implicaciones constituyan el significante de los

24 Otra opción es jerarquizar dependencialmente la estructura interna de la palabra y considerar que en el interior de la misma el tema rige a su vez a las categorías morfológicas. En el nivel superior la rección es ahora mantenida entre temas. No me interesan los detalles de estas alternativas sino tan solo la constatación de que, en cualquier caso, la rección no se establece entre las categorías morfológicas de una palabra y las de otra.

2s. A no ser que por manifestación de relaciones sintácticas (p.e. concordancia) se entiendan los cambios fonológicos en las formas de las palabras, con lo que en tal caso se regresaría al reconocimiento de la naturaleza exclusivamente fónica de la sustancia de la expresión del morfema. 
morfemas. Los argumentos anteriores atestiguan, en mi opinión, la necesidad de distinguir con nitidez entre aquello que constituye definitoriamente una unidad y aquello que, sin formar parte de ella, puede contribuir a constatar su presencia; entre aquellos elementos que de forma específica constituyen la manifestación sustancial de su significante y aquellos otros que, sin que ésta sea su función, pueden ayudar a la identificación del mismo en una secuencia concreta. Este último es el papel que corresponde a la combinatoria sintáctica en relación a las categorías morfológicas; papel importante si tenemos en cuenta que lo fónico, en tanto perteneciente al estrato sustancial, está sujeto a fenómenos de alomorfia, homonimia y amalgama que pueden dificultar o impedir en determinados contextos la identificación del valor lingüístico expresado.

Hechos sintácticos perfectamente reglados como la concordancia pueden permitir recuperar esa información de manera inmediata (crisis importantes). Otras veces los mecanismos son más indirectos, exigen la acumulación de un número mayor de factores, su sistematicidad es menor o su ámbito de actuación es más restringido (Cfr. la serie de marcas de plural citadas por Whorf). Y es que en los enunciados lingüísticos las relaciones de implicación, restricción e interrelación entre unidades y niveles pueden dar como resultado un cierto grado de «redundancia», no necesariamente interpretada como la expresión repetida de un mismo valor, sino como la posibilidad de deducir la existencia del mismo, aun cuando su realización no sea concluyente, a partir de la presencia, sí inequívoca, de otros. Ello, en cualquier caso, no autoriza a considerar que los elementos que nos pueden servir para determinar la presencia de ese valor sean su significante o formen parte de éste.

Lo anterior no debe interpretarse como una minusvaloración del papel de la combinatoria sintáctica en relación a las categorías. Se trata de asignarle el valor que, creo, le corresponde, no de negarle la rentabilidad que sin duda posee. En este sentido, el mismo valor informativo que cualquier hecho sintáctico de sistematicidad probada tiene en ocasiones para el hablante puede convertirse en valor metodológico para el lingüista. Ello no sólo en casos en que la manifestación sustancial puede ser circunstancialmente homónima (crisis/crisis), sino, sobre todo, en aquellos otros en los que los afijos muestran escasa regularidad o, simplemente, no existen.

Teniendo presentes las precisiones anteriores, y diferenciando por tanto entre lo teórico y lo metodológico al considerar la combinatoria en el nivel morfológico, planteamientos como el de Whorf o el de Fernández Pérez poseen el máximo interés desde este segundo punto de vista al mostrar la necesidad de abrir las puertas a una vía de identificación de valores morfológicos que sólo limitadamente ha sido explotada ${ }^{26}$ : la sintáctica.

26 Es el caso del género, cuya justificación sintáctica se encuentra ya en los orígenes clásicos de su estudio. 


\subsubsection{La sustancia del significante exclusivamente fónica}

Planteamientos como el de Hockett (1961) o el de Fernández Pérez coinciden, de manera acertada, en la negación del carácter fónico del significante de los signos mínimos (léxicos, derivativos o flexivos para Hockett y sólo estos últimos para Fernández Pérez). El significante como tal -esto es, en el cstrato de la forma- no está compuesto de fonemas. Sin embargo, y frente a las alternativas planteadas por estos autores, nada impide, a mi modo de ver, que se pueda considerar que el significante de los signos mínimos tiene como único medio de realización sustancial el fónico. Esta postura, por otra parte, y al menos en lo concerniente a los signos mínimos flexivos, encaja con las opiniones de Hjelmslev (1928). También Hockett (1958) y Lyons (1968) han defendido esta postura.

El análisis de Hjelmslev (1928) resulta particularmente interesante por cuanto su concepto de imagen gramatical ha sido citado con frecuencia como fuente de la visión no fónica del significante. En esta obra, Hjelmslev representa «la entidad con la cual debe operar la lingüística» mediante el siguiente esquema (Hjelmslev, 1928: 123):

$\operatorname{Signo}^{27}=$
$=$ significado $\underbrace{(\text { imagen fónica }+ \text { imagen gramatical) }}_{=\text {significante }}$

Para comprender su concepción del significante es necesario precisar el contenido de las nociones de imagen fónica e imagen gramatical (también denominada forma ${ }^{28}$ ) y aclarar, asimismo, cuáles son las relaciones que ambos tipos de imágenes contraen.

El concepto de imagen fónica no presenta problemas. La imagen fónica de un signo está constituida por un fonema o un conjunto de fonemas ${ }^{29}$. Menos transparente resulta la noción de imagen gramatical o forma. Hjelmslev distingue dos aspectos en ella:

27 Hjelmslev considera dos tipos de signos mínimos, los semantemas por un lado (lo que, con otra terminología, se conoce como raíces) y los morfemas por otro (los elementos derivativos y flexivos que se añaden a la raíz). En la introducción al libro, Hjelmslev (1928: 10) señala que, aunque la distinción entre morfema y semantema es capital, todavía se está lejos de su justificación, por lo que no se ocupará de ella en este trabajo.

Puesto que mi interés se centra en las categorías morfológicas, en lo que sigue prescindiré de someter a análisis las opiniones de Hjelmslev sobre los semantemas.

is Aunque este término se emplea también a lo largo de la obra con otros valores, relacionados pero distintos.

29) Hjelmslev habla de dos tipos de unidades fónicas. El término genérico que los recubre a 
Hay que entender por forma no sólo la forma del signo mismo, tomada aisladamente, sino igualmente la forma que impone cl signo a la scrie articulatoria en que se integra (Id: 128).

A la hora de aclarar el valor de la forma, sin embargo, Hjelmslev sólo se ocupa de la parte o dimensión combinatoria de ésta: la función, entendiendo por ella «la facultad de un elemento de combinarse exclusivamente con algunos otros elementos dados» (Id: 134). La función, por tanto, es una parte de la forma; pero una parte de la que carecen los morfemas. Hjelmslev es tajante:

El término de función gramatical no se aplica nunca a los morfemas. Únicamente los semantemas pueden tener una función (Id: 130) ${ }^{30}$.

Para la otra parte de la forma, la única que poseen los morfemas, Hjelmslev no concreta cuáles son sus rasgos específicos. De su tratamiento se deduce que la forma, en este sentido, no puede ser definida más que por su relación con un significado. Carece, en este nivel de abstracción, de otros rasgos positivos. En resumen, la imagen gramatical de los morfemas no posee para Hjelmslev (1928), a diferencia de la de los semantemas, valor combinatorio ${ }^{31}$.

Pero queda otro problema: ¿imagen fónica y gramatical se sitúan al mismo nivel en el interior del significante? A propósito de la imagen fónica, Hjelmslev reitera dos ideas complementarias que nos pueden ayudar a comprender la posición que ésta ocupa. Por una parte, insiste en que la imagen gramatical es independiente de la imagen fónica. Lo único decisivo en términos gramaticales es la forma, no los fonemas ${ }^{32}$. En consecuencia, la imagen fónica debe estar subordinada, en el nivel del signo, a la imagen gramatical.

ambos es el de fonema. Los fonemas-significantes son las unidades fónicas simples o complejas asociadas a un morfema, a un semantema o una palabra. A los fonemas no vinculados a unidades gramaticales, Hjelmslev los denomina sonidos. Los fonemas-significantes constituyen, pues, la imagen fónica de los signos. Fonema-significante y sonido se vienen a corresponder con los conceptos actuales de morfo y de fonema respectivamente.

30. En concreto, por función gramatical (de un semantema) se entiende:

1) la facultad de combinarse exclusivamente con ciertos morfemas dados, y

2) la facultad de combinarse con los otros semantemas exclusivamente por medio de cicrtos morfemas dados (Hiclmslev, 1928: 130).

3 No obstante, Hjelsmlev no siempre mantiene con coherencia sus opiniones anteriores. En unos casos concede tal importancia a la función que llega directamente a afirmar que «todo lo que es de orden gramatical es de orden sintagmáticos (Id: 161), identificando asíla forma con la función y olvidándose de los morfemas. En otras ocasiones, por el contrario, la función es ignorada y el semantema se define como la asociación entre identidades fónicas e identidades significativas (Cfr. Id: 177 y 179). Entre ambos extremos hay un margen amplio para la variación y, por tanto, para la ambiguedad. De todos modos, la caracterización que se ha presentado anteriormente es la que mejor debe representar el pensamiento del autor puesto que ha sido extraída del capítulo en el que éste aborda de forma explícita el tema de la forma gramatical.

32 De hecho, las evidentes diferencias entre las lenguas en cuanto a sus procedimientos fónicos de expresión no les impide, sin embargo, manifestar en ciertos casos oposiciones gramati- 
Por otro lado, Hjelmslev es igualmente claro respecto de la necesidad de que esas diferencias fónicas existan puesto que son el único medio a través del cual la forma se materializa. El significante expresa el significado y la imagen fónica expresa, a su vez, la imagen gramatical ${ }^{33}$.

Por tanto, la existencia de imágenes fónicas (o fonemas-significantes) distintas para formas gramaticales distintas se reconoce como imprescindible. Las características concretas de esas imágenes son, desde el punto de vista gramatical, intrascendentes ( $o$, con un término que Hjelmslev utiliza en alguna ocasión -Cfr. Id: 122 y 123 -, convencionales). Lo relevante para la gramática es la constatación de su existencia; su estudio, en cambio, no compete sino a la fonología ${ }^{34}$.

En síntesis, imagen gramatical e imagen fónica no se integran en pie de igualdad en el interior del significante, sino que, más bien, la imagen gramatical constituye en exclusiva el significante, mientras que la imagen fónica supone la materialización de éste en un nivel distinto. Empleando conceptos que el propio Hjelmslev se encargaría de reelaborar y divulgar más tarde, creo que el par forma/sustancia es el que mejor permite dar cuenta de las relaciones entre ambos tipos de imágenes tal como Hjelmslev (1928) las describe: la imagen gramatical es (la forma d)el significante y la imagen fónica su sustancia ${ }^{35}$.

cales idénticas (Cfr. Hjelmslev, 1928: \$ 19). Asimismo, en el interior de una lengua existen diferencias fónicas que no se corresponden con diferencias de forma gramatical, y formas gramaticales distintas que se cxpresan mediante el mismo material fónico, lo que prueba la relativa independencia de ambos aspectos (Cfr. Id: 124-125). Ciertos cambios fónicos, además, pueden estar supeditados a la necesidad de mantener determinadas distinciones morfológicas (Cfr. Id: 9495).

3.3 El significado sólo existe por medio del significante [...]. La forma, por su parte, sólo puede hallarse mediante el aspecto fónico. Un elemento gramatical existe únicamente por medio de el o los fonema(s) que lo expresa(n) [...]: el aspecto fónico debe permitirnos, por su estructura misma, detectar la forma (Hjelmslev, 1928: 161-162).

34 Disciplina cuyo objeto de estudio es el fonema y, por tanto (Cfr. n. 29), se debe ocupar tanto del sonido como del fonema-significante. El estudio fonológico de estas unidades debe incluir el de sus combinatorias, lo que HjelmsIev llama funciones fónicas (Cfr. 1928: 134). Téngase en cuenta que:

a) estas funciones son fonológicas, no gramaticales; no afectan, p.e., a los morfemas, sino a sus imágenes fónicas.

b) mientras que para Hjelmslev ( 1928) las funciones gramaticales - como parte de la forma $y$, por tanto, del significante- son elementos constitutivos de los semantemas, las funciones fónicas son externas a unas unidades (los fonemas) previamente fundadas sobre otros criterios. Dicho de otro modo, Hjelmslev (y a diferencia de lo que defenderá posteriomente) no define los fonemas (significantes o sonidos) por su combinatoria, sino que se limita a señalar que éstos, definidos y delimitados mediante otros criterios, poseen también ciertas características sintagmáticas.

35 Pero cuando Hjelmslev desarrolla la distinción entre forma y sustancia y le otorga un puesto esencial en su teoría, su concepción gramatical, teórica e incluso epistemológica ha variado de forma considerable, de tal modo que ya no se puede aplicar al estado de cosas descrito anteriormente (Cfr. 1938, 1939a y 1939b). Como detalle particular, obsérvese cómo en (1939b) la rección pasa a considerarse directamente establecida entre los morfemas de las palabras relacionadas sintácticamente, lo que supone invertir las características que en (1928) se atribuían a la función. 
Hockett (1958: 123) define los morfemas como «the smallest individually meaningful elements in the utterances of a language» (Cfr. n. 15). Para su identilicación, Hockett propone la búsqueda segmentos fónicos recurrentes, dotados de un contenido constante, que no sean segmentables en elementos menores del mismo tipo (esto es, recurrentes y significativos). Hockett advierte, sin embargo, de las dificultades a que puede conducir la exigencia de identidad fónica de los segmentos, algo que, de hecho, no fue incluido en su definición del morfema. Unidades fonémicamente distintas pueden ser expresión, en diferentes contextos, de un mismo contenido; y viceversa: un mismo segmento fónico puede expresar contenidos distintos. En consecuencia, Hockett distingue entre morfema y shape. Aunque la distinción, como hemos visto, no es en absoluto nueva, lo interesante es la descripción que Hockett efectúa de las relaciones entre ambos tipos de entidad:

For the relationship of a morpheme to any of its phonemic shapes, we use the phrase is represented by: the English noun plural morpheme is represented by phonemic shape $/ \mathrm{z} /$ after a form ending in $/ \mathrm{d} /$, and is represented by $/ \mathrm{s} /$ after a form ending in $/ \mathrm{t} /$; the English morpheme boy is represented by the phonemic shape /bój/ in all environments (Hockett, 1958: 135).

La comparación con la que Hockett ilustra la naturaleza de la relación de representación es suficientemente reveladora:

We have used the same phrase for the relationship between a phoneme and any of its allophones: the English phoneme $/ \mathrm{p} /$ is represented by a voiceless unaspirated bilabial stop after $/ \mathrm{s} /$, before a vowel, but by a voicelss aspirated bilabial stop initially before a stressed vowel (Ibid.).

En términos de la tradición estructural europea, es la dicotomía forma vs. sustancia la que da cuenta de las relaciones entre fonemas y fonos. De forma similar, pues, los phonemic shapes constituyen las realizaciones sustanciales de los morfemas ${ }^{26}$.

Lyons (1968) es totalmente explícito al respecto. Después de establecer la distinción entre morfema (unidad gramatical) ${ }^{37}$ y morfo (segmento fónico de la palabra), comenta:

36 Las únicas realizaciones sustanciales, por otra parte. En el otro estrato, el formal, el morfema se concibe como una unidad puramente distintiva (Cfr. 1958: 134). Los morfemas poseen diversas posibilidades distributivas (arrangements), de cuyo estudio se encarga también la gramática, pero Hockett (1958) en ningún momento acude a las mismas como medio de definición o identificación de los morfemas. La combinatoria es, por tanto, un rasgo adicional que caracteriza a los morfemas pero que no los define ni individualiza.

37 Lyons sí caracteriza al morfema como unidad distribucional, más en concreto como componente o factor distribucional de las palabras, prescindiendo en todo momento de cualquier recurso al significado. La concepción de Lyons (1968), pues, enlaza con la tradición distribucional 
La distinción que hemos sentado aquí entre morfos y morfemas puede asimismo expresarse a base de la distinción de Saussure entre substancia y forma. Lo mismo que todas las demás unidades gramaticales, el morfema es un elemento de «forma», relacionado «arbitrariamente» con su realización «substancial» a nivel fonológico [...] de la lengua (Lyons, 1968: 189).

Más adelante, insiste:

Lo que tiene una importancia particular es la distinción entre morfema y morfo, entre la unidad gramatical y su correspondiente representación «substancial». Gracias a esta distinción podemos aclarar tanto la similitud gramatical como la diferencia formacional que existe entre palabras tales como quiso y temió, o menor y más fácil. En la parte puramente gramatical de la descripción pueden indicarse de un modo semejante tanto las formas «regulares» como las «irregulares»:

$\{$ quer $\}+\{i o ́\},\{1 e m+i o ́\},\{m a ́ s\}+\{$ pequeño $\},\{m a ́ s\}+\{$ fácil $\}$; etcétera.

La diferencia entre las formas «regulares» y las formas «irregulares» se descubre en el punto de la descripción en que las palabras, como unidades puramente gramaticales, se «encarnan», como si dijéramos, en una substancia fonológica [...] (Id: 192-193).

Asumo plenamente el contenido de las citas de Lyons siempre y cuando - y al igual que antes fue señalado respecto de Hockett (Cfr. n. 15) - éste interprete que el elemento conectado en términos de forma-sustancia con el morfo es el significante del signo mínimo. Éste es el único valor que se puede conceder al término morfema si se pretende que la descripción de sus relaciones con el morfo sea correcta ${ }^{38}$.

\section{Conclusiones: el significante del signo mínimo y su sustancia}

Mi propuesta, a la luz de todo lo anterior, se resume en los puntos siguientes: i. La existencia de fenómenos como la alomorfia, la amalgama o la homonimia pone de manifiesto que el significante del signo mínimo (y, en general,

más estricta, representada paradigmáticamente por la obra de Harris y continuada, al menos en parte, por los primeros modelos generativos. En cualquier caso, Lyons no precisa (como tampoco lo hace Matthews, 1974, 1991) cuál es el estatus semiótico (significante, significado o signo) de esta entidad.

38 Lyons se equivoca, en cambio, si por morfema entiende el significado del signo mínimo o el signo mínimo en su conjunto. Los elementos de un plano no pueden tener como manifestación sustancial hechos pertenecientes al otro. Interpretar el morfo como sustancia de un significado sería, pues, totalmente inapropiado. Por su parte, el signo no posec otra realización sustancial que las de su significante y su significado, por lo que tampoco se puede considerar que el morfo es una representación del signo en su integridad. En consecuencia, o el morfema de Lyons es un significante o el concepto de «representación sustancial» que este autor maneja supone una tergiversación de la dicotomía estructural forma vs. sustancia. 
cualquier significante) no tiene carácter fónico: no es un agregado de fonemas. Se trata de una unidad formal, abstracta, que, a diferencia de lo que sucede con otros tipos de unidades formales, no es definible por otro rasgo positivo que su vinculación biunívoca con un significado.

ii. Eliminada la exigencia de un segmento fónico específico para poder hablar de un significante $y$, por tanto, de un signo, no existen inconvenientes para considerar que la entidad semiótica que corresponde a las categorías morfológicas es la de signo mínimo. Como denominación lingüística para el mismo, en adelante será utilizado el término morfema.

iii. Las categorías morfológicas no son el único tipo de morfemas existentes en las lenguas. Al lado de las categorías morfológicas (morfemas flexivos) es necesario considerar la existencia de morfemas léxicos y derivativos.

iv. Al igual que cualquier otra unidad formal, el significante del morfema se manifiesta sustancialmente, en este caso a través de secuencias fónicas (morfos, exponentes o formantes ${ }^{39}$ ). Los morfos son una unidad puente entre la gramática (realizan significantes) y la fonología (están compuestos de fonemas), sin que ello pueda ser aducido como argumento contra su realidad empírica. Los morfos constituyen un claro ejemplo de relativismo en la conformación de los planos y estratos del lenguaje: lo que puede ser contemplado como forma en un nivel (combinaciones de fonemas) es al mismo tiempo sustancia desde otro (realizaciones de significantes).

v. El significante del morfema no está constituido, ni siquiera parcialmente, por sus posibilidades combinatorias. Las exigencias/restricciones a la presencia de valores categoriales en determinadas combinatorias:

a) son una exigencia sintáctica, no morfológica. La participación sintáctica de las categorías morfológicas es una posibilidad que deriva de (pero no constituye) las propiedades definitorias de éstas;

b) afectan a unidades previamente constituidas sobre bases autónomas, morfológicas y no sintácticas, estáticas y no combinatorias. Las exigencias/ restricciones combinatorias pueden servir de indicador de la presencia de un significante, pero no constituyen la manifestación sustancial de éste, no son el medio a través del cual éste se concreta; y

c) se apoyan en el carácter fónico de la sustancia del significante de los morfemas.

vi. Las categorías morfológicas, pues, han de ser identificadas a partir del aislamiento y conmutación de sustancias de la expresión (diferencias fónicas) y del contenido en el nivel de la palabra. Puesto que la conmutación opera con sustancias, es preciso tener en cuenta lo indicado en el punto siguiente.

39) Que, cuando son sustancia de un mismo significante, pueden recibir el nombre de alomorfos 0 alternantes. 
vii. La relación entre forma y sustancia no es necesariamente biunívoca. Por tanto, cabe la posibilidad -explotada en mayor o menor grado según lenguas y ámbitos morfológicos- de que un morfo exprese más de un significante al mismo tiempo (amalgama), de que morfos distintos —en principio, en contextos diferentes- expresen el mismo significante (alomorfia) o, incluso, de que el mismo morfo exprese significantes distintos (homonimia). Es posible, además, que una categoría morfológica sea expresada mediante cambios en la raíz de la palabra, esto es, el morfo normalmente asociado con la expresión sustancial del significante de un morfema léxico. Así sucede en lo que se conoce como supletivismo. Desde el punto de vista gramatical todos estos fenómenos son irrelevantes puesto que remiten al estrato de la sustancia.

viii. Otro fenómeno de sustancia que ha de ser considerado es la manifestación de un valor categorial mediante un morfo cero (carente de expresión fonemática). La lengua se limita a explotar lo que constituye un procedimiento de realización comunicativa generalmente utilizado en cualquier sistema semiótico. La ausencia de expresión fónica es un medio totalmente eficaz (y absolutamente económico) de realización sustancial de un significante cuando éste se opone a otro u otros que sí poseen algún tipo de manifestación material.

ix. Los hechos de amalgama y de supletivismo revelan la necesidad, claramente constatable en determinadas lenguas y/o en ciertos dominios de éstas, de atender a la palabra como un todo a la hora de aplicar la conmutación y, por tanto, al identificar las categorías que funcionan en una lengua y describir la organización interna de las mismas. En vez de buscar segmentos fónicos específicos, se tratará, pues, de comprobar la existencia de una palabra fonológica distinta - reconocida a partir de cualquier tipo de cambio fonológico- como correspondencia a una agrupación distinta de valores categoriales (palabra gramatical). Ésta es, por ejemplo, la metodología empleada por Veiga (Cfr. $1990)^{4 !}$.

$x$. El grado de amalgama en la expresión de las categorías (y, por tanto, el grado en que la palabra puede ser segmentada en morfos constitutivos) es el principal criterio para realizar la conocida distinción entre lenguas aglutinantes (cuyo tipo puro se caracterizaría por la inexistencia de hechos de amalgama) y lenguas flexivas. Esta tipología, en cualquier caso, no concierne a la estructura gramatical de las lenguas sino a su representación mórfica, sustancial (Cfr. Lyons, 1968:199).

41) La posibilidad de homonimia impide, en cualquier caso, una aplicación ciega de este procedimiento metodológico. Así, por ejemplo, la conmutación entre los contenidos de persona primera y tercera en el contexto morfológico singular, co-pretérito, IND 0 no provoca ningún cambio en el verbo español (cantaba / cantaba), sin que ello implique la existencia de neutralización de esa oposición en el entorno mencionado. 
xi. De todo lo anterior se desprende la necesidad de distinguir dos ámbitos o subámbitos disciplinares: uno, estrictamente gramatical, ocupado de la identificación y descripción de los morfemas como unidades formales, y, especialmente en el caso de las categorías morfológicas, responsable del estudio de la organización interna de sus paradigmas. Sólo al segundo, encargado del estudio de las relaciones entre el significante del morfema y sus manifestaciones sustanciales en el plano de laexpresión (morfos), le interesa la segmentación interna de las palabras. Sin entrar ahora en la discusión terminológica, podemos hablar de morfología en el primer caso y de morfofonología (la morfofonémica de Hockett, 1958:\$ 15.3) en el segundo, teniendo presente, por otra parte, que morfología se puede emplear también en un sentido general, inclusivo, por lo que quizá sería conveniente designar la vertiente formal de esta morfología amplia como morfémica ${ }^{41}$. Lo importante, en cualquier caso, es que ambas áreas se diferencien con claridad y no se condicione el reconocimiento de entidades gramaticales por factores que, como la existencia de un segmento fónico independiente, son gramaticalmente secundarios (sustanciales).

xii. La morfofonología de una lengua debe ser estudiada. Por obvias razones de exhaustividad descriptiva en primer lugar. La utilización de un modelo descriptivo de palabra y paradigma es suficiente (además de ser con frecuencia necesario, como hemos señalado) para identificar los miembros y los sistemas de oposiciones de las categorías morfológicas en una lengua. Desde el punto de vista de una descripción global de esa lengua, el análisis será más completo si se especifican, además, las sustancias que en el plano de la expresión realizan los significantes de estos signos. Pero existen, además, intereses teóricos. Las relaciones entre forma y sustancia y, en este caso, entre gramática y fonología, no son necesariamente biunívocas, pero tampoco son arbitrarias. Elementales razones de eficacia comunicativa y economía (en la expresión, el aprendizaje, la memorización, la percepción, etc.) restringen notablemente las posibilidades a este respecto y revelan el carácter excepcional que en relación a las categorías morfológicas poseen hechos como la homonimia ${ }^{42}$ o el supletivismo ${ }^{43}$. Considé-

41 Como propone Fernández Pérez (1991), y a diferencia de lo que por morphenics entiende Hockett (1958: 276).

42 En el caso de unidades en oposición directa. No sucede así, sin embargo, con elementos opuestos por más de una valor categorial al tiempo. En este caso, y como Veiga ha mostrado en relación al sistema verbal de lenguas como el español (Cfr. 1992), una misma palabra fonológica puede ser expresión de varias palabras gramaticales. Es interesante comprobar entonces cómo por cconomía, en un sistema tan complejo como el verbal, la lengua sólo distingue abiertamente aquello que, por diferenciarse por un único rasgo de contenido, es más fácilmente confundible. En casos de oposición mediante más de una categoría, la lengua delega en el contexto y la situación.

43. En general, la irregularidad morfofonológica en la manifestación de una oposición categorial, cuyo extremo se halla representado por los casos de supletivismo, es un hecho de extensión limitada y que sólo se mantiene en aquellos casos en los que las unidades afectadas presentan altos índices de liecuencia (Cfr. Bybee, 1985). 
rese también, por ejemplo, la tendencia a que los miembros gramaticalmente no marcados de una categoría sean expresados mediante morfos cero ${ }^{44}$.

De acuerdo con lo defendido en este trabajo, las categorías morfológicas no poseen una constitución semiótica exclusiva, no son el único tipo de morfema. La individualización de las mismas, por tanto, debe realizarse acudiendo a algún otro rasgo definitorio adicional. Éste es, en mi opinión, la sistematicidad en dos vertientes: externa (integración de sus miembros en paradigmas) y externa (productividad y regularidad en las combinaciones con los temas de las palabras). No otra cosa es lo que debe entenderse por flexión.

Por otra parte, la visión de las categorías morfológicas como morfemas ( $y$, por tanto, unidades compuestas de significante y significado) plantea ciertas dificultades en relación con algunas de ellas. Es el caso, entre otras, del género. Ello puede llevar a replantear o matizar la entidad sígnica que aquí se ha concedido al concepto de categoría morfológica, pero, y como se señalaba en la introducción, un análisis de las categorías que parta de esta consideración inicial es la mejor forma de comprender la heterogeneidad real de lo habitualmente incluido bajo esta etiqueta. El género, además, no sólo muestra importantes peculiaridades en relación a otras categorías, sino que se revela como un dominio en sí mismo heterogéneo, integrado, incluso en una lengua, por fénómenos que deben ser cuidadosamente deslindados.

El inexcusable estudio de estos aspectos supera, sin embargo, los límites del presente trabajo.

44 Cfr., también, algunas de las observaciones contenidas en Jakobson (1949). 


\section{Referencias bibliográficas}

Alarcos, E. (1977): «Metodología estructural y funcional en lingüística», Revista Española de Lingüistica 7/2 (1977), 1-16.

Alarcos, E. (1978): «Unités distinctives et unités distinctes», La Linguistique 14/2 (1978), 39-53.

Álvarez, R., H. Monteagudo \& X.L. Regueira (1986): Gramática Galega, Vigo, Galaxia, 1986.

Bosque, I. (1989): Las Categorias Gramaticales, Madrid, Síntesis, 1989.

Bybee, J.L. (1985): Morphology. A Study of the Relation between Meaning and Form, Amsterdam, John Benjamins, 1985.

Coseriu, E. (1981): Lecciones de lingüística general, Madrid, Gredos, 1981.

Fernández Pérez, M. (1986): «Las disciplinas lingüísticas», Verba 13 (1986), 15-73.

Fernández Pérez, M. (1991): «Sobre el concepto de morfema y el ámbito de la Morfologia», Verba 18 (1991), 27-68.

Fernández Pérez, M. (1993): Las categorias gramaticales (morfológicas) en español, Universidade de Santiago de Compostela, 1993.

Gutiérrez, S. (1981): Lingüística y Semántica (Aproximación funcional), Universidad de Oviedo, 1981.

Gutiérrez, S. (1983): «La determinación inmanente de las funciones en sintaxis», Contextos 1/2 (1983), 41-56.

Gutiérrez, S. (1989): Introducción a la Semántica Funcional, Madrid, Síntesis, 1989.

Harris, Z.S. (1942): «Morpheme alternants in linguistic analysis», Language 18 (1942), 169-180.

Hjelmslev, L. (1928): Principes de grammaire générale (=Historik-filologiske XVI, I), Det Kogenlige Danske Videnskabernes Selskab, 1928. Utilizo la trad. esp. de F. Piñeiro, Principios de gramática general, Madrid, Gredos, 1976.

Hjelmslev, L. (1938): «Essai d'une théorie des morphèmes», Actes du IVe Congrès international de linguistes 1936, Copenhague, 140-151. Utilizo la trad. esp. de F. Piñero, «Ensayo de una teoría de los morfemas», Ensayos lingiǘsticos, Madrid, Gredos, 1972, 200-217.

Hjelmslev, L. (1939a): «La structure morphologique (types de système)», Vme Congrès international des linguistes, Rapports, Bruges, 1939, 66-93. Utilizo la trad. esp. de F. Piñero, «La estructura morfológica», Ensayos lingüísticos, Madrid, Gredos, 1972, 147-181.

Hjelmslev, L. (1939b): «La notion de rection», Acta Linguistica I (1939), 1023. Utilizo la trad. esp. de F. Piñero, «La noción de rección», Ensayos lingüísticos, Madrid, Gredos, 1972, 182-199. 
Hockett, Ch.F. (1947): «Problems of morphemic analysis», Language 23 (1947), 321-343.

Hockett, Ch.F. (1958): A Course in Modern Linguistics, New York, The Macmillan Company, 1958.

Hockett, Ch.F. (1961): «Linguistic elements and their relations», Language 37/ 1 (1961), 29-53.

Jakobson, R. (1949): «The phonemic and grammatical aspects of language and their interrelations», Actes du VIr Congrès International des Linguistes (Paris, 1949), 5-18. Trad. esp. de J. Cabanes, «Los aspectos fonémicos y gramaticales de la lengua en sus interrelaciones», Ensayos de linguiística general, Barcelona, Ariel, 1984, 217-234.

Jespersen, O. (1924): The Philosophy of Grammar, London, George Allen \& Unwin Ltd. Utilizo la trad. esp. de C. Manzano (a partir de la $10^{\mathrm{a}}$ ed. inglesa, 1968), La filosofia de la gramática, Barcelona, Anagrama, 1975.

Lyons, J. (1968): Introduction to Theoretical Linguistics, Cambridge University Press, 1968. Utilizo la trad. esp. de R. Cerdà (1971), Introducción en la lingüística teórica, Barcelona, Teide, $1986^{8}$.

Marcos Marín, F. (1980): Curso de gramática española, Madrid, Cincel, 1980. Martinet, A. (1960): Éléments de linguistique générale, Paris, Armand Colin, 1960. Utilizo la trad. esp. de J. Calonge, Elementos de lingüística general, Madrid, Gredos, 1968.

Martinct, A. (1985): Syntaxe générale, Paris, Armand Colin, 1985. Utilizo la trad. esp. de A. Yllera y J.F. Corcuera, Sintaxis general, Madrid, Gredos, 1987.

Martínez, J.A. (1977): «Los elementos de la gramática y el género en castellano», Estudios ofrecidos a Emilio Alarcos Llorach, Vol. I, Universidad de Oviedo, 1977, 165-192. Utilizo su reedición con ligeras modificaciones en Propuesta de gramática funcional, Madrid, Istmo, 1994, 153-194.

Martínez, J.A. (1994): «El funcionalismo gramatical del español», Propuesta de gramática funcional, Madrid, Istmo, 1994, 17-120.

Matthews, P.H. (1974): Morphology. An introduction to the study of wordstructure, Cambridge University Press, 1974.

Matthews, P.H. (1991): Morphology, $2^{a}$ ed., Cambridge University Press, 1991. Moreno Cabrera, J.C. (1991): Curso universitario de lingüistica general. I: Teoría de la gramática y sintaxis general, Madrid, Síntesis, 1991.

Pena, J. (1990): «Sobre los modelos de descripción morfológica», Verba 17 (1990), 5-75.

Pena, J. (1991a): «Consideraciones en torno a la palabra y al morfema», M. Brea \& F. Fernández Rei (eds.), Homenaxe ó profesor Constantino García, Vol. I, Universidade de Santiago de Compostela, 1991, 365-373.

Pena, J. (1991b): «La palabra: estructura y procesos morfológicos», Verba 18 (1991), 69-128. 
Rojo, G. (1979): «La función sintáctica como forma del significante», Verba 6 (1979), 107-151.

Sánchez de las Brozas, F. (1587), Minerva, Salamanca, 1587. Utilizo la trad. esp. de F. Rivera Cárdenas, Madrid, Cátedra, 1976.

Sánchez Ruipérez, M. (1954): El sistema de tiempos y aspectos del verbo griego antiguo. Análisis funcional sincrónico, Universidad de Salamanca-Consejo Superior de Investigaciones Científicas, 1954.

Stockwell, R.P., J.D. Bowen \& J.W. Martin (1965): The Grammatical Structures of English and Spanish, The University of Chicago Press, 1965.

Swadesh, M. \& C.F. Voegelin (1939): «A problem in phonological alternation», Language 15 (1939), 1-10.

Trujillo, R. (1976): Elementos de semántica lingüística, Madrid, Cátedra, 1979².

Veiga, A. (1990): «Planteamientos básicos para un análisis funcional de las categorías verbales en español», G. Wotjak \& A. Veiga (eds.), La descripción del verbo español, Universidade de Santiago de Compostela, 1990 , 237-257.

Veiga, A. (1992): Condicionales, concesivas y modo verbal en español, Universidade de Santiago de Compostela, 1992.

Whorf, B.L. (1945): «Grammatical categories», Language 21 (1945), 1-11. Utilizo su reimpresión en J.B. Carroll (ed.) (1956), Language, Thought, and Reality. Selected Writings of Benjamin Lee Whorf, Cambridge (Mass.), The MIT Press, 1973, 87-101. 